\title{
$\mathrm{CFD}$ 를 이용한 유동제어 핀의 최적설계
}

위다얼 $\cdot$ 김동준 ${ }^{1}$

부경대학교 조선해양시스템공학과

\section{The Design Optimization of a Flow Control Fin Using CFD}

\section{Da-Eol Wie' Dong-Joon Kim.}

Department of Naval Architecture and Marine Systems Engineering, Pukyong National University ${ }^{1}$

\begin{abstract}
In this paper, the Flow Control Fin(FCF) optimization has been carried out using computational fluid dynamics(CFD) techniques. This study focused on evaluation for the performance of the FCF attached in the stern part of the ship. The main advantage of FCF is to enhance the resistance performance through the lift generation with a forward force component on the foil section, and the propulsive performance by the uniformity of velocity distribution on the propeller plane. This study intended to evaluate these functions and to find optimized FCF form for minimizing viscous resistance and equalizing wake distribution. Four parameters of FCF are used in the study, which were angle and position of FCF, Iongitudinal location, transverse location, and span length in the optimization process. KRISO $300 K$ VLCC2(KVLCC2) was chosen for an example ship to demonstrate FCF for optimization. The optimization procedure utilized genetic algorithms (GAs), a gradient-based optimizer for the refinement of the solution, and Non-dominated Sorting GA- I(NSGA- I) for Multiobjective Optimization. The results showed that the optimized FCF could enhance the uniformity of wake distribution at the expense of viscous resistance.
\end{abstract}

Keywords : Computational fluid dynamics (전산유체역학), Flow control fin(유동제어 핀), Multiobjective optimization(다목적 최적화)

\section{1. 서 론}

선박의 이산화탄소 배출 규제 실행과 연료 가격의 상승에 의해 친환경선박이 주목을 받고 있다. 새로운 선박설계에서는 에너지 효율 향상을 위하여 우수한 저항 성능을 가진 선형을 개발하거나 선체표면에 부가물을 부착함으로써 선형의 유체역학적 성능 향상 을 통하여 에너지 절감의 효과를 보고자 하는 것이 대부분이다.

Lee, et al.(2004)은 40,000 톤급 정유 운반선에 와류 생성기 (vortex generator)를 부착하여 선미 변동압력을 감소시키는 방법 을 제시하였다. Jang, et al.(2006)은 CFD기법을 활용하여 와류 생성기를 설계하고 모형시험을 통하여 실선에서의 속도 및 캐비 테이션 성능을 확인하였다.

Choi, et al.(2009)은 KCS선형에 유동제어판을 부착하여 선체 에 미치는 영향을 유체역학적 관점에서 연구하였다. 유동제어판 을 부착하였을 때 선체의 자세와 조파저항계수의 변화를 확인하 였고, $\mathrm{KCS}$ 선박의 경우 선수트림이 발생하여 조파저항계수가 감 소하는 것을 볼 수 있었다.

Park, et al.(2009)은 유동제어판(Flow Control Plate)의 효과 를 활용하여 저항과 추진성능의 향상을 확인하였다. Lee (2011) 은 Wake Equalizing Duct을 부착하여 선체 저항 변화와 반류 분 포 변화를 확인하였다.
본 연구에서는 선미 유동 제어 장치로서 유동제어 핀(Flow Control Fin, FCF)을 부착하여 반류개선에 따른 선체 저항 변화 와 공칭반류의 변화를 확인하고자 한다. 그리고 점성저항과 반류 분포의 향상을 목적으로 하는 FCF의 최적설계를 수행하였다. KVCC2를 대상선박으로 사용하였으며 수치해석은 상용 유동해 석 프로그램인 CFX를 사용하였다. 그리고 최적화는 Ansys 12의 $\mathrm{GDO}$ (Goal Driven Optimization)을 사용하였다. FCF의 선형, 부 착 위치, 부착 각도을 알기 위하여 설계변수를 설정하고 점성저 항과 반류분포를 목적함수로 하여 FCF을 이용한 에너지 효율향 상 선박을 설계하고자 한다.

\section{2. 대상선박 및 수치해석}

\section{1 대상선박의 선정}

Fig. 1 Kriso 300K VLCC (KVLCC2)

KVCC2(Fig. 1)는 MOERI(구 KRISO)에서 설계되었고 모형실 험 결과가 공개되어 있는 KRISO 300K VLCC (KVCC2)이며, Yang, et al.(2010)과 Kim, et al.(2005)에 의해 연구되었다. 
본 연구는 KVCC2의 $1 / 58$ 의 축척비를 가지는 모형시험과 동 일한 조건에서 수치계산을 수행하였다. Table 1는 KVLCC2의 기 본 제원을 나타내었다.

Table 1 Principal particulars of KVLCC2

\begin{tabular}{c|c|c}
\hline & KVCC2 & KVCC2 Model \\
\hline Scale & \multicolumn{2}{|c}{58.0} \\
\hline$L p p(m)$ & 320 & 5.5172 \\
\hline$B(m)$ & 58.0 & 1.0000 \\
\hline$T(m)$ & 20.8 & 0.3586 \\
\hline$D(m)$ & 30.0 & 0.5172 \\
\hline CB & 0.8098 & 0.8098 \\
\hline S.C.H. $(\mathrm{m})$ & 5.8 & 0.1 \\
\hline$F n$ & \multicolumn{2}{|c}{0.1423} \\
\hline Rn & 15.5 & $1.047(\mathrm{~m} / \mathrm{s})$ \\
\hline$U(\mathrm{kn})$ &
\end{tabular}

\section{2 좌표계 및 수치해석 방법}

수치계산을 위하여 적용된 좌표계는 Fig. 2에서 보는 바와 같 이 선체 길이 방향을 $x$ 축, 폭 방향이 $y$ 축, 연직 상방향이 $z$ 축으로 하는 직교 좌표계를 사용하였다. 좌표계의 원점은 선체 중심면과 중앙면 그리고 자유표면이 만나는 점을 잡았다.

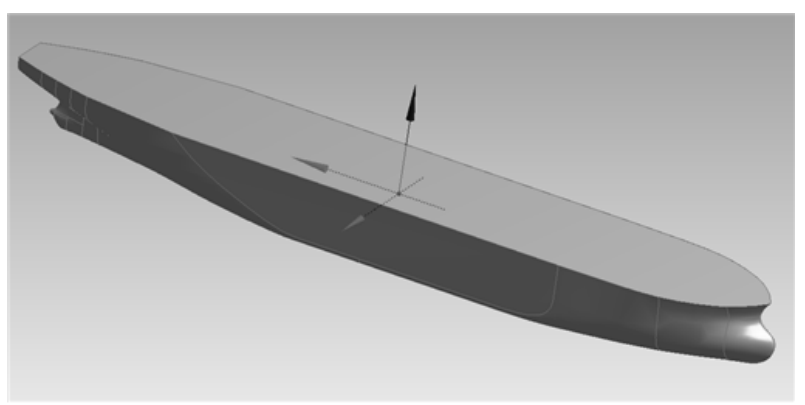

Fig. 2 Coordinates system

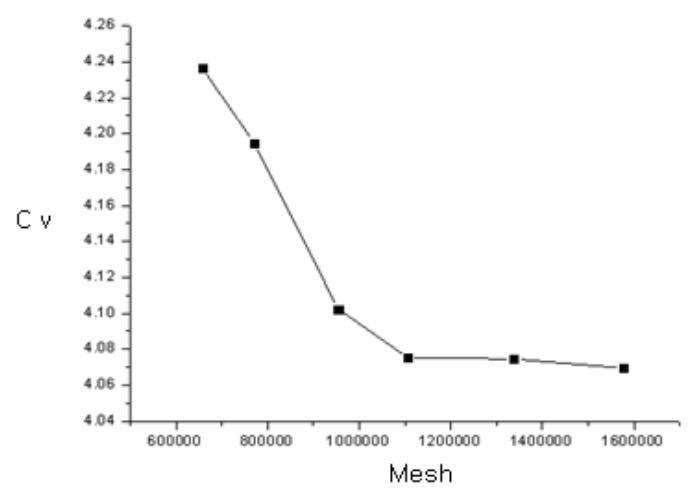

Fig. $3 \mathrm{Cv}$ by number of cells for the mesh sensitivity analysis (Lee, 2011)

본 연구에서는 상용프로그램 $\mathrm{CFX}$ 를 사용하였으며, 난류유동
의 지배방정식은 Reynolds-Averaged Navier-Stokes (RANS) 식 과 연속방정식을 사용하였다. 난류 모형은 standard $k-\varepsilon$ 모형을 사용하였으며 수치계산을 위한 격자는 Unstructured hybrid로 tetrahedral를 사용하였다. 그리고 $y^{+}$는 선행연구(Kim, et al., 2009; Kim \& Kim. 2006; Lee, 2011)에서 제시된 80으로 설정하 였다. Fig. 3은 Lee (2011)에서 수행하였던 KVCCC2를 CFX를 사 용하여 $y^{+}$을 80 으로 고정하고 격자의 수에 따른 점성저항계수의 값을 나타낸다. 격자의 수가 약 110 만개를 넘어가면서 점성저항계 수의 값이 $1 \%$ 이하의 오차를 보이며 변화하는 것을 확인 할 수 있 으므로 격자의 수렴성이 확보되었다고 판단된다. 따라서 본 연구 에서는 $y^{+}$를 80 으로 설정하고 약120만개의 격자를 사용하였다. 각각의 경계면에 주어진 경계조건과 계산조건은 Table 2 와 같다.

Table 2 Computational conditions

\begin{tabular}{c|c}
\hline & 내용 \\
\hline CFD program & CFX, CFX-Mesh \\
\hline Govering equation & Reynolds-Averaged Navier-Stokes(RANS) \\
\hline Froude No & 0.1423 \\
\hline Reynolds No & $4.6 \times 10^{6}$ \\
\hline \multirow{4}{*}{ Boundary condition } & Inlet region: velocity Inlet u=1.047m/s \\
\cline { 2 - 2 } & Outlet region: static pressure $=0$ \\
\cline { 2 - 2 } & $\begin{array}{c}\text { Hull surface: wall } \\
\text { (no-slip condition) }\end{array}$ \\
\cline { 2 - 2 } Turbulent model & Remaining region: symmetry \\
\hline Mesh type & Standard $k-\varepsilon$ turbulent model \\
\hline$y^{+}$ & 80 \\
\hline
\end{tabular}

\section{3 수치해석의 결과와 CFX의 유용성 확인}

Table 3은 수치해석을 결과로 얻어진 마찰저항계수 $\left(\mathrm{C}_{F}\right)$, 점성 압력저항계수 $\left(\mathrm{C}_{\mathrm{VP}}\right)$, 마찰저항과 점성압력저항을 더한 점성저항계 수 $\left(C_{v}\right)$ 그리고 형상저항계수(1+k)를 그간 발표된 Yang, et al.(2010), Kim, et al.(2008)의 수치해석 결과와 비교한 것이다. 형상저항계수는 Hino (2005)가 추천한 식을 사용하였으며 계산 에 사용된 평판의 마찰저항계수(CFO)는 ITTC-1957의 공식을 사 용하였다. 본 수치해석에서 구한 각종 저항계수의 값은 Yang, et al.(2010), Kim, et al.(2008)에서 구한 값들의 사이에 있음을 확 인 할 수 있다.

Table 3 Resistance coefficients (KVLCC2)

\begin{tabular}{c|c|c|c|c}
\hline & $\mathrm{CF}\left(\times 10^{3}\right)$ & $\mathrm{Cvp}\left(\times 10^{3}\right)$ & $\mathrm{Cv}\left(\times 10^{3}\right)$ & $1+\mathrm{k}$ \\
\hline ITC & 3.450 & & & \\
\hline $\begin{array}{c}\text { Yang, et } \\
\text { al.(2010) }\end{array}$ & 3.211 & 0.677 & 3.888 & 1.127 \\
\hline $\begin{array}{c}\text { Kim, et } \\
\text { al.(2008) }\end{array}$ & 3.374 & 0.913 & 4.287 & 1.1243 \\
\hline Author & 3.2167 & 0.8563 & 4.073 & 1.183 \\
\hline
\end{tabular}


Fig. 4는 프로펠러 평면에서의 공칭반류분포(nominal wake distribution)의 모습을 보여주고 있다. KVCC2와 같은 저속비대 선의 경우, 선미부의 만곡부와류에 의해서 공칭반류분포가 갈고 리 모양으로 나타나는데 Fig. 4에서 확인 할 수 있다. Yang, et al.(2010)에서 구한 공칭반류분포의 모양은 공칭반류속도가 0.3 1의 범위에서 수행되어지고 본 연구는 $0.1 \sim 0.9$ 의 범위에서 수행됨으로써 중앙주위의 저속구간이 더 세밀하게 묘사되고 있으 며, 전체적인 형상이 잘 일치함을 확인할 수 있다.

저항계수의 값과 공칭반류분포의 모양이 선행연구의 수치결과 가 잘 일치하므로 상용 유동 해석프로그램인 CFX의 유용성을 확 인 할 수 있었다.
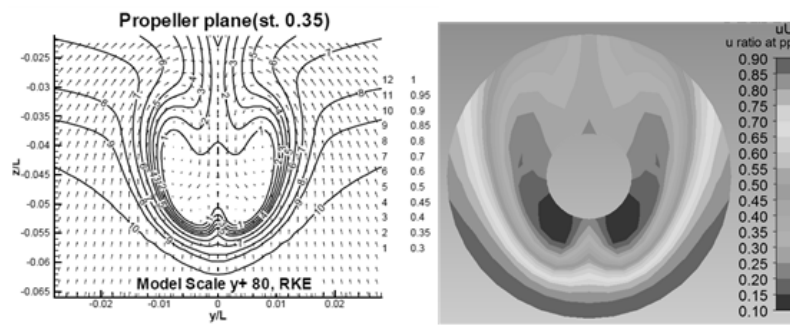

Fig. 4 Axial velocity distribution on the propeller of KVLCC2 (Left: Yang, et al., 2010, Right: Author)

\section{Flow Control Fin의 설계}

\subsection{Fin의 제원}

Choi, et al.(2009)은 KCS선형에 유동제어판을 부착하여 선체 에 미치는 영향을 유체역학적 관점에서 연구하였다. 조파저항계수 및 선수미 침하량 관점에서 가장 우수한 것으로 코드길이는 $2.0 \mathrm{~m}$, 스팬길이는 $1.5 \mathrm{~m}$ 로 선정되었다.

본 연구에서는 $\mathrm{KVCC} 2$ 가 $\mathrm{KCS}$ 에 비하여 만곡부와류와 박리에 의한 저항증가와 반류의 불균등정도가 크기 때문에 $\mathrm{FCF}$ 의 성능을 확인하기에 적합하다고 판단하여 부착대상선박으로 선정하였다. $\mathrm{KCS}$ 와 KUCC2의 길이비에 따른 코드길이를 설정하였다. 코드길 이/스팬길이가 0.5 가 되는 스팬길이를 초기 FCF의 제원으로 설정 하고 코드길이/스팬길이가 $0.7(25 \%) ~ 2.1(75 \%)$ 의 스팬길이를 설계변수로 설정하여 연구를 수행하였다. Table 4는 Choi, et al.(2009)의 유동제어판과 FCF의 제원을 비교한 것이다.

Table 4 Comparison of chord and span length

\begin{tabular}{c|c|c|l}
\hline & Plate & Fin & \\
\hline 대상선박 & KCS & KVCC & \\
\hline $\mathrm{L}(\mathrm{m})$ & 230 & 320 & \\
\hline Chord length $(\mathrm{m})$ & 2 & 2.8 & \\
\hline Span length $(\mathrm{m})$ & 1.5 & 1.4 & $0.7(25 \%) \sim 2.1(75 \%)$ \\
\hline
\end{tabular}

Fig. 5는 초기부착위치에서 -0.85 Chord length 0.85 Chord length의 설계변수에 따른 FCFP(Flow Control Flat Plate)
와 FCF의 점성저항 수치를 나타낸다. FCFP(Flow Control Flat Plate)보다 FCF를 부착하였을 때 점성저항이 작은 수치가 나타남 을 확인하였다. 그러므로 목적함수인 점성저항 관점에서 Plate보 다 Fin이 우수하기 때문에 선미유동제어장치로써 Fin형상을 부착 하는 것이 적절하다고 판단된다. (Wie, 2011) FCF의 단면형상으 로 NACA 0012 (Fig. 6)를 사용하였다. 이는 대칭성의 형상으로 서 익형의 기초연구에 자주 사용되며 $\mathrm{t}($ 최대 두께 $)=\mathrm{c} \times 12 \%=2$ $\times 0.12=0.24 \mathrm{~m}$ 이다.

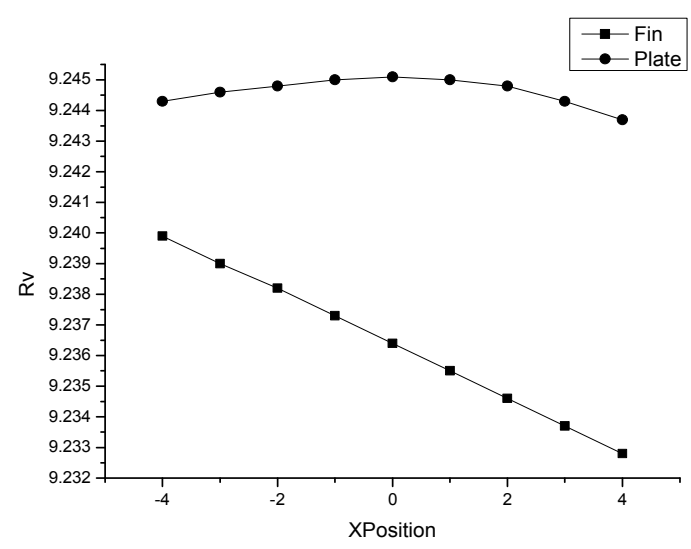

Fig. 5 Rv of FCF and FCFP

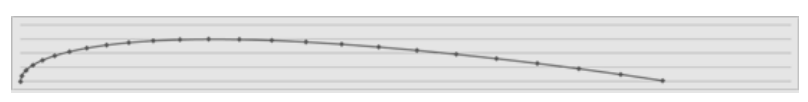

Fig. 6 Profile section shape, NACA 0012

\section{2 $\mathrm{FCF}$ 의 초기위치}
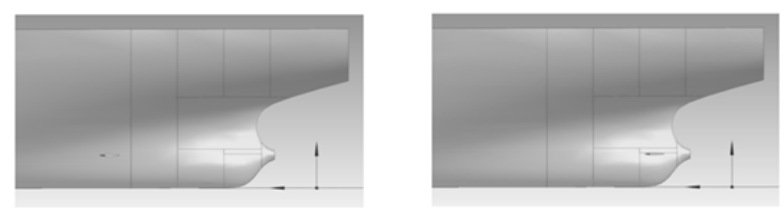

Fig. 7 Initial design variable of FCF (Left: $60 \mathrm{~cm}$, Right: $20 \mathrm{~cm}$ )

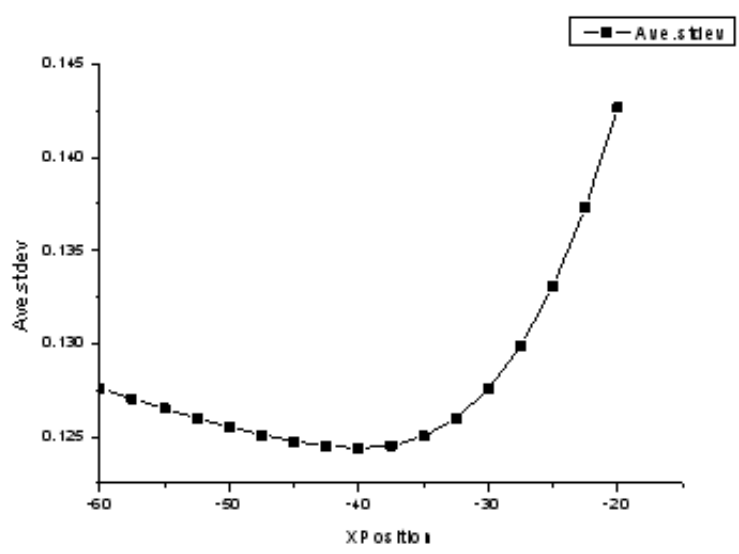

Fig. 8 Ave. stdev of initial design variable 
$\mathrm{FCF}$ 의 초기위치를 설정하기 위하여 Fig. 7과 같이 선체의 전 진방향을 $x$ 축, 폭 방향이 $y$ 축, 연직 상방향이 $z$ 축으로 하는 직교 좌표계를 사용하였다. $y$ 축은 FCF의 cord length/span length가 0.5 가 되는 지점을 설정하였고, $z$ 축은 프로펠러의 중심인 S.C.H(Shaft Center Height)로 설정하였다. 그리고 y축, $z$ 축은 고 정하고 $x$ 축에 초기설계변수로 $20 \mathrm{~cm} \sim 60 \mathrm{~cm}$ 를 설정하여 반류불 균등수치를 목적함수로 하여 수행하였다.

Table 5는 FCF의 $y$ 축과 $z$ 축의 부착위치, 각도로서 초기설계변 수의 고정되어있는 수치를 나타낸다. Fig. 8은 FCF를 x축을 따라 $20 \mathrm{~cm} \sim 60 \mathrm{~cm}$ 의 설계변수로 하여 목적함수인 반류불균등을 수 치계산 한 것이다. $x$ 축이 $40.004 \mathrm{~cm}$ 에서 가장 작은 반류불균등 수치를 얻었다. 그러므로 FCF의 초기부착위치는 Table 6의 좌표 로 설정하였다.

Table 5 Restrictive condition of initial FCF

\begin{tabular}{c|c|c|c}
\hline & Y Position & Z Position & Angle \\
\hline Initial FCF & $7.8 \mathrm{~cm}$ & $10 \mathrm{~cm}$ & 0 \\
\hline
\end{tabular}

Table 6 Coordinates of Initial position FCF

\begin{tabular}{c|c|c|c|c}
\hline & X Position & Y Position & Z Position & Angle \\
\hline Initial FCF $(\mathrm{cm})$ & 40.004 & 7.8 & 10 & $0^{\circ}$ \\
\hline
\end{tabular}

\section{4. 최적화}

본 연구에서 사용한 프로그램은 형상과 부착위치의 변형은 Design Modeler, 수치계산은 CFX, 최적화 기법은 Ansys의 $\mathrm{GDO}$ (Goal Driven Optimization)을 사용하여 수행하였다.

\section{1 설계변수}

본 연구는 $\mathrm{FCF}$ 의 초기위치에서 선미 길이방향을 $X$ 축, 폭 방향 을 Z축, 연직 상방향을 Y축으로 좌표축을 잡았다. 그리고 FCF의 $X$ 축 위치, $Y$ 축 위치, $Z$ 축 위치, $Z$ 축 의 각도를 설계변수로 사용 하였으며, 허용하한과 허용상한은 Table 7과 같다.

Table 7 Design variable of FCF

\begin{tabular}{c|c}
\hline & Design variable \\
\hline X Position & -0.85 Chord length $\sim 0.85$ Chord length \\
\hline Y Position & -Radius of Propeller/2 Radius of Propeller/2 \\
\hline Z Position & $\begin{array}{r}\text { Span/Chord length }=0.25 \sim \\
\text { Span/Chord length }=0.75\end{array}$ \\
\hline Z Angle & $-25^{\circ} \sim 25^{\circ}$ (반시계방향을 각도의 양의 방향) \\
\hline
\end{tabular}

\section{2 목적함수}

본 연구는 $\mathrm{FCF}$ 의 최적설계의 목적함수로 점성저항과 반류분
포의 균등정도를 사용하였다. 점성저항의 단위는 선체에 작용하 는 점성저항력의 크기 $(\mathrm{N})$ 를 사용하였다. 반류불균등 정도를 수치 화시키는 방법은 Lee (2011)에서 제시한 방법을 사용하였다. 프 로펠러 평면을 반경방향으로 $10^{\circ}$ 간격으로 나누었다. 그리고 $0.3 \mathrm{Rp} \sim 1.0 \mathrm{Rp}$ (여기서 $\mathrm{Rp}$ 는 프로펠러의 반경)까지 총 8개의 원 주로 나누고 교점에서의 종방향 유속을 구하여 각 반경별로 종방 향 유속의 표준편차를 계산하였다. 반경별 종방향 유속의 표준편 차의 평균값을 반류균등도 평가의 목적함수로 사용하였다.

\section{3 응답표면 생성}

$\mathrm{CFD}$ 를 이용한 최적설계의 시간을 줄이기 위하여 실험계획법 (DOE)을 통해 응답표면(response surface)을 생성하고 응답표면 에서 최적화 알고리즘을 적용하였다. 각 목적함수를 종속변수로 하고, 4개의 설계변수(X Position, Y Position, Z Position, Z Angle)를 독립변수로 하여 2차 다항함수로 표현된다. Fig. 9는 반 류불균등도(Ave.stdev)를 FCF의 Angle, Position의 함수로 표현 했을 때의 모양이다.
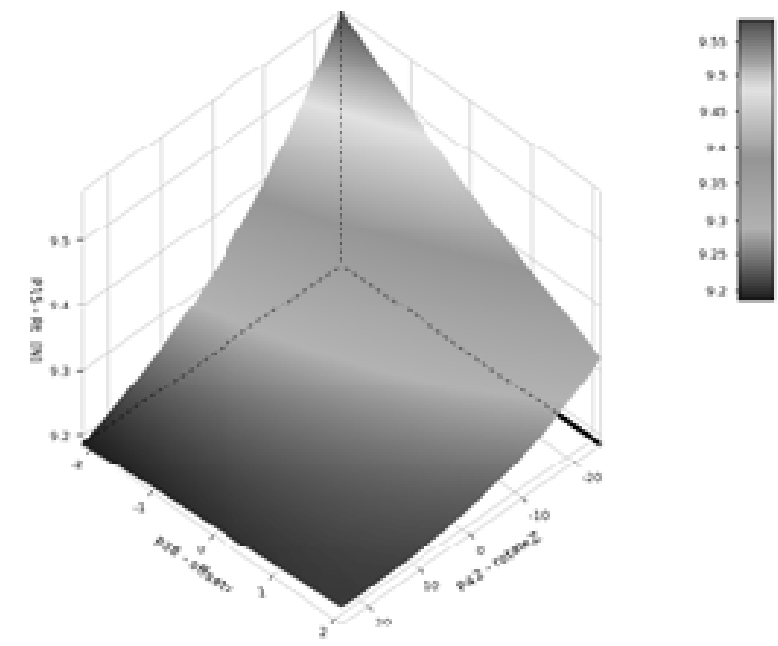

Fig. 9 Response surface of Ave.stdev

\section{5. 최적화 계산 결과}

본 연구는 전역해의 정확도를 높이기 위하여 최적화과정을 2 단계로 나누어 수행하였다. 첫 번째는 확률론적 최적화 기법인 알고리즘(Genetic Algorithm, GA)을 이용하여 전역해 근처의 해 를 찾았다. 두 번째 단계에서는 첫 번째 단계에서 도출된 해를 시 작점으로 하여 기울기 기반 최적화 기법인 NLPQL(Non Linear Programming by Quadratic Lagrangian, Schittkowski, 1985/86) 을 적용하였다.

\section{1 점성저항(RV) 최적화}

최소 점성저항을 가지는 최적화 과정을 수행하였고 그 결과 얻 
어진 $\mathrm{FCF}$ 의 부착위치와 제원은 Table 8과 같다.

Table 8 Location of FCF with minimum Rv

\begin{tabular}{c|c|c|c}
\hline X Position & Y Position & Span length & Z Angle \\
\hline-3.6765 & -0.42671 & 3.5729 & 21.994 \\
\hline
\end{tabular}

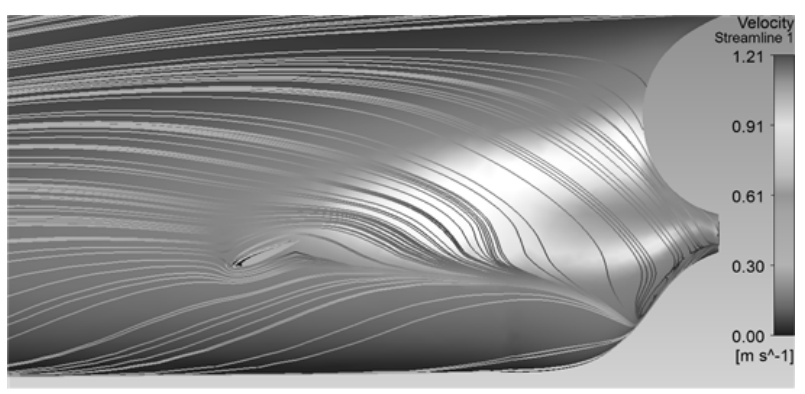

Fig. 10 Limiting streamlines of FCF with minimum Rv

Fig. 10은 최소 점성저항을 가지는 $\mathrm{FCF}$ 의 부착위치와 제원에 서의 한계유선(limiting streamlines)을 나타내고 있다.

Table 9 Comparison of hydrodynamic data of bare hull and hull with Rv optimized FCF

\begin{tabular}{c|c|c|c|c|c}
\hline & $\operatorname{Rv}(\mathrm{N})$ & $\operatorname{Rf}(\mathrm{N})$ & $\operatorname{Rvp}(\mathrm{N})$ & $\begin{array}{c}\text { Ave. } \\
\text { stdev }\end{array}$ & $\begin{array}{c}\text { Ave. } \\
\text { wake }\end{array}$ \\
\hline Bare hull & 9.1965 & 7.2477 & 1.9488 & 0.12763 & 0.37453 \\
\hline Rv Opt hull & 9.1965 & 7.2562 & 1.9403 & 0.13456 & 0.38084 \\
\hline
\end{tabular}

Table 9는 최소 점성저항을 가지는 FCF을 부착한 선박과 Bare hull의 점성저항과 반류불균등을 비교한 것이다. 점성저항은 같은 수치를 얻었고, 반류불균등도(Ave.stdev)는 0.00693만큼 증 가하는 결과를 가져왔으며 평균 공칭반류 값은 0.0063 만큼 증가 하였다. $\mathrm{FCF}$ 의 부착에 의하여 마찰저항(Rf)은 $0.0085 \mathrm{~N}$ 증가하였 지만 점성압력저항은 $0.0085 \mathrm{~N}$ 감소하였다. $\mathrm{FCF}$ 의 아랫면에서 압력이 낮이짐에 따라 유속이 빨라지면서 만곡부와류의 형성에 의한 3차원 박리(ordinary separation)현상이 줄어든 것으로 판단 된다.(Fig. 11) $\mathrm{FCF}$ 의 부착으로 인해 마찰저항은 증가하였지만 박리감소로 인하여 점성압력저항이 줄어들어 Bare hull 의 점성저 항과 같은 수치를 얻었다고 판단된다.
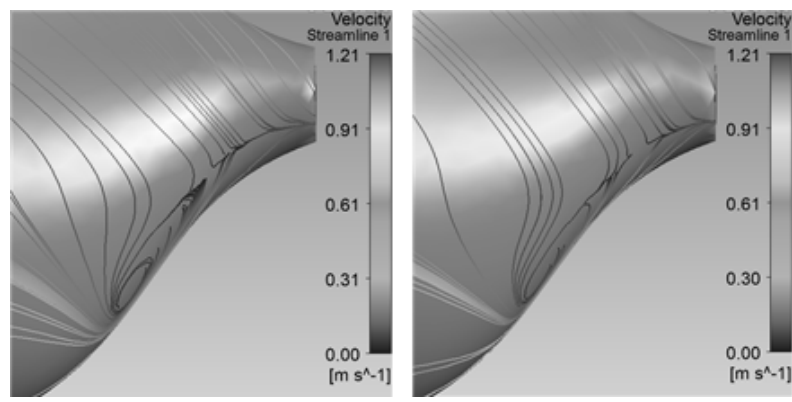

Fig. 11 Comparison of limiting streamlines (Left: Bare hull, Right: Rv opt hull)

\section{2 반류분포 최적화}

Table 10 Location of FCF with minimum RV

\begin{tabular}{c|c|c|c}
\hline$X$ Position & Y Position & Span length & $Z$ Angle \\
\hline 2.8133 & 2.1188 & 1.268 & -23.089 \\
\hline
\end{tabular}

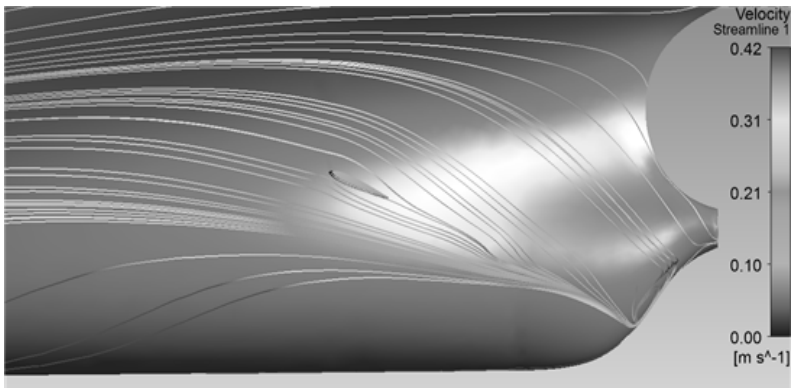

Fig. 12 Limiting streamlines of FCF with minimum Ave. stdev

최소 반류불균등수치를 가지는 최적화 과정을 수행하였고 그 결과 얻어진 FCF의 부착위치와 제원은 Table 10과 같다. Fig. 12 는 최소 반류불균등도를 가지는 $\mathrm{FCF}$ 의 부착위치와 제원에서의 한계유선(limiting streamlines)을 나타내고 있다.

Table 11 Comparison of hydrodynamic data of bare hull and hull with Ave. stdev optimized FCF

\begin{tabular}{c|c|c|c}
\hline & $\operatorname{Rv}(\mathrm{N})$ & Ave. stdev & Ave. wake \\
\hline Bare hull & 9.1965 & 0.12763 & 0.37453 \\
\hline Ave. stdev opt hull & 9.2465 & 0.11683 & 0.38073 \\
\hline
\end{tabular}

Table 11은 최소 반류불균등도를 가지는 FCF을 부착한 선박 과 Bare hull의 점성저항과 반류불균등을 비교한 것이다. 반류불 균등도는 0.0108 만큼 감소하였고 점성저항은 $0.05 \mathrm{~N}$ 증가하는 수 치를 얻었으며, 평균 공칭반류 값은 0.0062 만큼 증가하였다.
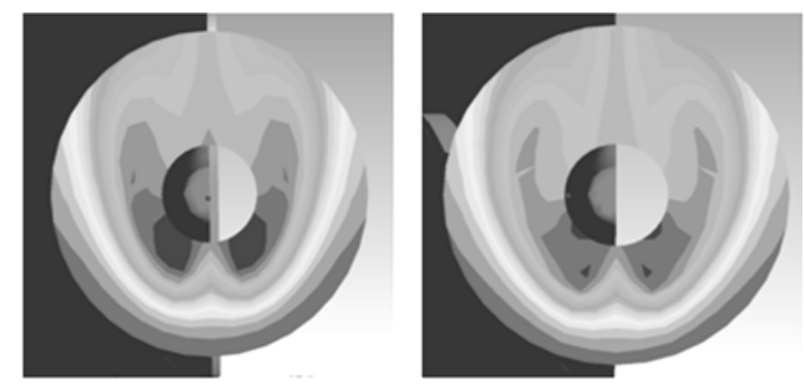

Fig. 13 Comparison of wake distribution at propeller plane of bare hull and hull with Ave. stdev optimized FCF (Left: Bare hull, Right: Ave. stdev opt hull)

Fig. 13은 Bare hull과 최소 반류불균등도를 가지는 FCF를 부 착한 선박의 반류 분포를 나타낸다. $\mathrm{FCF}$ 의 윗면에서 아랫면에 
비하여 빠른 유속을 가지기 때문에 Bare hull에 비하여 12시 구 간의 저속구간이 줄어든 것을 확인할 수 있으며 6시구간의 고속 구간이 줄어든 것을 볼 수 있다. 그리고 중앙부근의 저속구간영 역도 줄어 든 것을 볼 수 있다.

\section{3 점성저항과 반류분포의 다목적 최적화}

본 연구에서는 점성저항의 크기와 반류불균등 정도를 목적함 수로 하는 FCF의 다목적 최적화를 수행하기 위해 비지배 정렬을 기반으로 하고 다목적 함수 최적화 문제에 널리 사용되는 NSGAII (Non-dominated Sorting GA-II, Deb, et al. 2002)를 사용하 였다.

Table 12는 초기위치의 FCF을 부착한 선박과 Bare hull의 점 성저항과 반류불균등을 비교한 것이다. $\mathrm{FCF}$ 의 초기부착위치는 길이방향의 $x$ 축의 초기변수에 따른 반류불균등 수치가 최소가 되 는 위치로 선정하였다. 따라서 반류불균등도는 0.00529 만큼 감 소하였고 점성저항은 $0.0462 \mathrm{~N}$ 증가하는 수치를 얻었으며, 평균 공칭반류 값은 0.00292만큼 증가하였다.

최소의 점성저항과 반류불균등도를 동시에 만족하기 위해서는 목적함수의 가중치를 다르게 두고 다목적최적화를 수행하는 것이 바람직하다고 판단하였다. 점성저항은 $75 \%$, 반류불균등도는 $25 \%$ 로 가중치를 설정하고 최적화를 수행하였다.

Table 12 Comparison of hydrodynamic data of bare hull and hull with Initial FCF

\begin{tabular}{c|c|c|c}
\hline & $\operatorname{Rv}(N)$ & Ave. stdev & Ave. wake \\
\hline Bare hull & 9.1965 & 0.12763 & 0.37453 \\
\hline Initial FCF hull & 9.2427 & 0.12234 & 0.37745 \\
\hline
\end{tabular}

Table 13은 최소의 점성저항과 반류불균등도를 동시에 만족하 는 파레토 최적해 집합으로서 $\mathrm{FCF}$ 의 부착위치와 제원에 따른 목 적함수의 값을 계산한 결과이다. 최적해집합에서 최소의 반류불 균등도를 가지는 3 번의 FCF의 제원과 부착위치를 선택하여 한계 유선(limiting streamlines)과 반류분포를 확인하였다.

Table 13 Comparison of optimum FCF and objective function

\begin{tabular}{c|c|c|c|c|c|c|c}
\hline & $\begin{array}{c}X \\
\text { Position }\end{array}$ & $\begin{array}{c}\text { Y } \\
\text { Position }\end{array}$ & $\begin{array}{c}\text { Span } \\
\text { length }\end{array}$ & $\begin{array}{c}Z \\
\text { Angle }\end{array}$ & $\operatorname{Rv}(\mathrm{N})$ & $\begin{array}{c}\text { Ave. } \\
\text { sdtev }\end{array}$ & $\begin{array}{l}\text { Ave. } \\
\text { wake }\end{array}$ \\
\hline 1 & 3.9992 & 2.125 & 1.2014 & -24.495 & 9.2277 & 0.1186 & 0.38215 \\
\hline 2 & 3.9992 & 2.0264 & 1.2014 & -24.495 & 9.2564 & 0.12001 & 0.38158 \\
\hline 3 & 2.8133 & 2.1132 & 1.2378 & -22.763 & 9.2337 & 0.11689 & 0.38049 \\
\hline
\end{tabular}

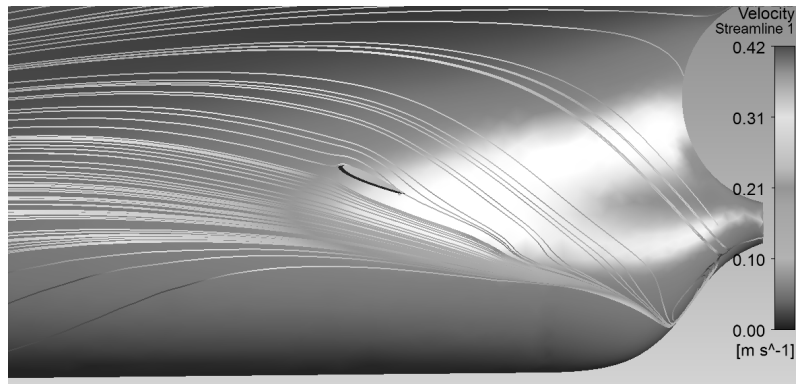

Fig. 14 limiting streamlines of Multiobjective optimized FCF

Fig. 14는 최소의 점성저항과 반류불균등도를 동시에 만족하는 $\mathrm{FCF}$ 의 부착위치와 제원에서의 한계유선(limiting streamlines)을 나타내고 있다. Table 14의 최소의 점성저항과 반류불균등도를 동시에 만족하는 FCF을 부착한 선박과 Bare hull의 점성저항과 반류불균등을 비교한 것이다. 반류불균등도는 0.01074 만큼 감소 하였고 점성저항은 $0.0372 \mathrm{~N}$ 증가하는 수치를 얻었으며, 평균 공 칭반류 값은 0.00596 만큼 증가하였다.

Table 14 Comparison of hydrodynamic data of bare hull and hull with Multiobjective optimized FCF

\begin{tabular}{c|c|c|c}
\hline & $\operatorname{Rv}(\mathrm{N})$ & Ave. stdev & Ave. wake \\
\hline Bare hull & 9.1965 & 0.12763 & 0.37453 \\
\hline Multiobjective opt hull & 9.2337 & 0.11689 & 0.38049 \\
\hline
\end{tabular}

Fig. 15는 Bare hull과 최소의 점성저항과 반류불균등도를 동 시에 만족하는 FCF를 부착한 선박의 반류 분포를 나타낸다. $\mathrm{FCF}$ 의 윗면에서 이랫면에 비하여 빠른 유속을 가지기 때문에 Bare hull에 비하여 12시 구간의 저속구간이 줄어든 것을 확인할 수 있으며 6시구간의 고속구간이 줄어든 것을 볼 수 있다. 그리 고 중앙부근의 저속구간영역도 줄어 든 것을 볼 수 있다.
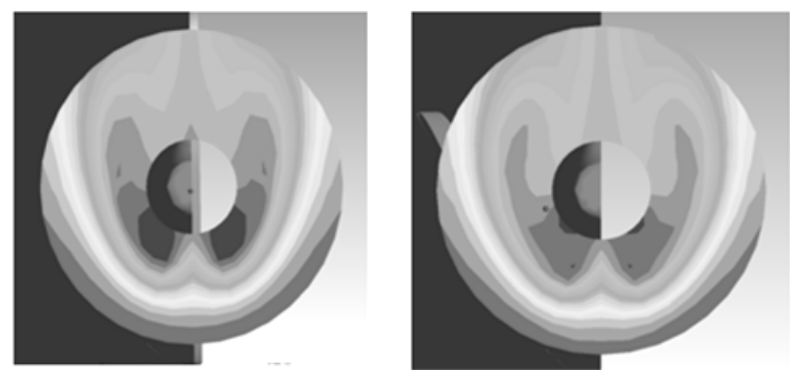

Fig. 15 Comparison of wake distribution at propeller plane of Bare hull and hull with Multiobjective optimized FCF (Left: Bare hull, Right: Multiobjective opt hull)

Fig. 16은 Bare hull과 최소의 점성저항과 반류불균등도를 동 시에 만족하는 $\mathrm{FCF}$ 의 프로펠러 반경별 반류불균등도를 나타내고 있다. 0.3R에서는 Bare hull보다 반류불균도가 높은 수치를 나타 
내지만 $0.4 \mathrm{R} \sim 1.0 \mathrm{R}$ 에서 낮은 수치를 나타내어 전체적인 반류불 균등도가 낮은 수치를 얻은 것으로 판단된다.

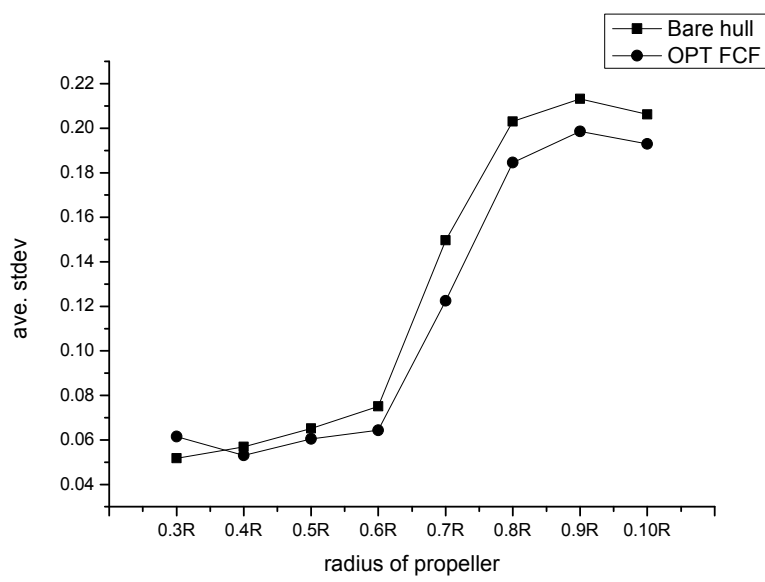

Fig. 16 Distribution of computational ave. stdev

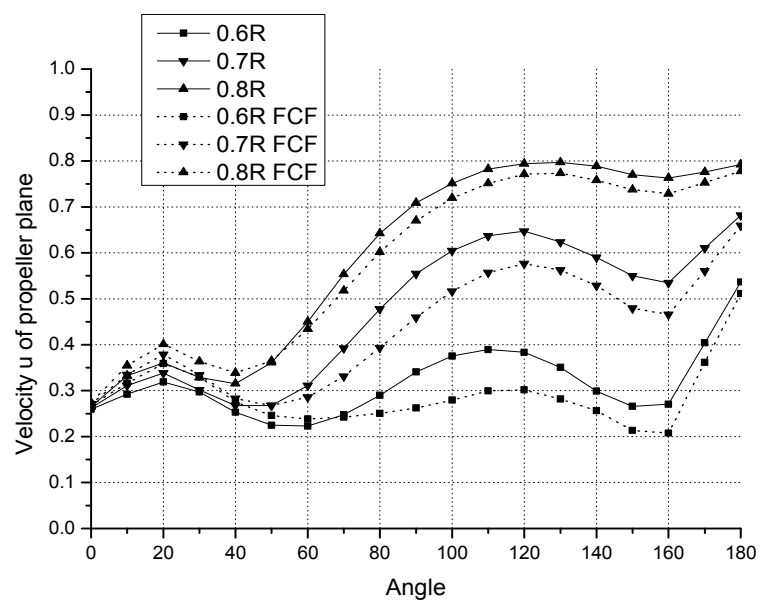

Fig. 17 Distribution of computational velocity $u$

Fig. 17은 Bare hull과 최소의 점성저항과 반류불균등도를 동 시에 만족하는 FCF의 0.6R, 0.7R, 0.8R에서의 각도별 종방향 유 속을 나타내고 있다. $0 \sim 45$ 구간의 저속영역에서는 Bare hull보 다 속도가 증가하였고, $45 \sim 180$ 구간에서는 속도가 감소하였 다. 저속구간의 속도는 증가하고 고속구간의 속도는 감소하여 반 류불균등도의 수치가 줄어든 것으로 판단된다.

\section{6. 결 론}

본 연구에서는 선미 유동 제어 장치로서 Flow Control Fin을 부착하여 반류개선에 따른 선체 저항 변화와 공칭반류의 변화를 확인하고자 하였다. 그리고 점성저항과 반류 분포의 향상을 목적 으로 하는 $\mathrm{FCF}$ 의 최적설계를 수행하였다. $\mathrm{FCF}$ 의 선형, 부착 위 치, 부착 각도을 알기 위하여 설계변수를 설정하고 점성저항과 반류분포를 목적함수로 하여 FCF을 이용한 에너지 효율향상 선
박을 설계하고자 하였다. 전역해의 정확도를 높이기 위하여 확률 론적 최적화 기법인 알고리즘(Genetic Algorithm, GA)과 기울기 기반 최적화 기법인 NLPQL(Non Linear Programming by Quadratic Lagrangian, Schittkowski 1985/86)을 적용하여 FCF 를 점성저항과 반류분포의 관점에서 각각 최적화를 수행하였다.

1. 점성저항 최적화에서 Bare hull의 점성저항과 같은 수치를 얻었고, 반류불균등도(Ave. stdev)는 증가함으로써 반류불균등 정도가 증가하는 결과를 가져왔다. $\mathrm{FCF}$ 의 부착에 의하여 마찰저 항(Rf)은 증가하였지만 점성압력저항은 감소하였다.

2. 반류분포 최적화에서 반류불균등도는 감소하였고 점성저항 은 증가하는 수치를 얻었다. Bare hull에 비하여 12시 영역과 중 앙부근의 저속구간이 줄었고, 6 시영역의 고속구간이 줄어든 것을 확인할 수 있었다.

3. 점성저항과 반류분포의 다목적 최적화에서 반류불균등도는 $8.4 \%$ 감소하였고 점성저항은 $0.4 \%$ 증가하는 수치를 얻었다. 0 $\sim 45^{\circ}$ 구간의 저속영역에서는 Bare hull보다 속도가 증가하였고, $45^{\circ} 180^{\circ}$ 구간에서는 속도가 감소하였다. 저속구간의 속도는 증 가하고 고속구간의 속도는 감소하여 반류불균등도의 수치가 줄어 든 것으로 판단된다.

본 연구를 통하여 반류분포의 균일성을 향상시킬 수 있는 FCF 의 제원과 부착위치를 찾음으로써, FCF로 인한 에너지 효율선박 의 가능성을 확인할 수 있었다. 하지만 다목적 최적화를 수행할 경우 점성저항의 증가를 가져왔다. 점성저항과 반류분포를 동시 에 향상시키기 위해서 FCF의 다양한 단면형상과 설계변수영역의 확대에 대한 연구가 필요하다고 생각된다. 그리고 FCF주위의 난 류유동을 좀 더 정확하게 표현할 수 있는 난류모델에 의한 연구 가 필요하다고 생각된다. 또한, 반류분포의 균일도에 따른 유체 역학적 성능향상의 정량적 연구가 필요하다고 생각된다.

\section{후 기}

본 논문은 교육과학기술부 2010년 선정과제 지역혁신인력 양성사업(100125)의 지원으로 연구되었습니다.

\section{참 고 문 헌}

Choi, H.J. Chun, H.H. Yoon, H.S. Lee, I.W. Park, D.W. \& Kim, D.J., 2009. Potential Flow Analysis for a Ship with a Flow Control Plate near the Stern. Journal of the Society of Naval Architects of Korea, 46(6), pp.587-594.

Deb, K. Pratap, A. Agrawal, S. \& Meyarivan, T., 2002. A Fast and Elitist Multiobjective Genetic Algorithm: NSGA-II. 
Institute of Electrical and Electronics Engineers Transactions on Evolutionary Computation, 6(2), April. 2002, pp. 182-197.

Hino, T., 2005. Proceedings of CFD Workshop Tokyo. Tokyo, Japan, 2005.

Jang, Y.H. Park, J.J. Kim, B.G. \& Choi, Y.B., 2006. Notes on the Design and Application of Vortex Generators. Proceeding of the Annual Autumn Meeting the Society of Naval Architects of Korea, pp.467-472.

Kim, H.T. \& Kim, H.T., 2006. Research of Elements Giving Effects on the Nunerical Analysis for the LNG Carrier. Journal of the Society of Naval Architects of Korea, 43(6), pp.656-666.

Kim, B.N. Kim, W.J. Kim, K.S. \& Park, I.R., 2009. The Comparison of Flow Simulation Results around a KLNG Model Ship. Journal of the Society of Naval Architects of Korea, 46(3), pp.219-231.

Kim, H.J. Chun, H.H. An, N.H., 2008. Hull Form Optimization using Parametric Modification Functions and Global Optimization. Journal of the Society of Naval Architects of Korea, 45(6), pp.590-600.

Kim, J. Park, I.R. Kim, K.S. \& Van, S.H., 2005. RANS Simulations for KRISO Container Ship and VCC Tanker. Journal of the Society of Naval Architects of Korea, 42(6), pp. 593-600.

Lee, H.S., 2011. The Design Optimization of a Wake Equalizing Duct Using CFD. Master Thesis. Pukyong National University.
Lee, C.J. Park, I.R. Lee, Y.H. \& Byeon, S.H., 2004. A Study on the Performances Affected by Vortex Generator for DWT 40,000Ton Product Carrier. Proceedings of the Annual Autumn Meeting the Society of Naval Architects of Korea, Sancheong, 20-22 October, 2004, pp.257-263.

Park, D.W. Choi, H.J. Yoon, H.S. \& Chun, H.H., 2009. A Numerical Study for Improvement of the Speed-performance of a Ship with Flow Control Flat Plate. Journal of the Society of Naval Architects of Korea, 46(3), pp.268-278.

Schittkowski, K., 1985/86. NLPQL: A FORTRAN subroutine solving constrained nonlinear programming problems. Annals of Operations Research, 5(2), pp.485-500.

Wie, D.E., 2011. The Design Optimization of a Flow Control Fin Using CFD. Master Thesis. Pukyong National University.

Yang, H.U. Kim, B.N. Yoo, J.H. \& Kim, W.J., 2010. Wake Comparison between Model and Full Scale Ships Using CFD. Journal of the Society of Naval Architects of Korea, 47(2), pp.150-162.
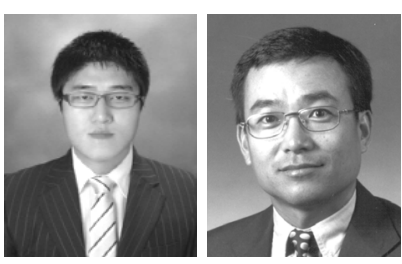

위 다 얼 